\title{
El quirófano: entre recomendaciones científicas y el arte de operar
}

\author{
The operating room: between scientific recommendations and the art of operating
} Juan David Lobo-Hernández

Estudiante de Medicina, XI semestre. Facultad de Ciencias de la Salud, Universidad del Quindío. Armenia, Colombia

"Ojos de águila, manos de seda y corazón de león". Astler P. Cooper

Esta disciplina maravillosa de la medicina, exige de quien busca practicarla una actitud tenazmente perseverante. Esa naturaleza impredecible de la propia vida se encarna en síntomas y signos que experimenta desde su mente una persona, de allí que la infinidad de patologías que producen sufrimiento en esta especie, en suma, a la cultura, que definen la forma de manifestar las dolencias, suponen un mundo interminable de descripciones científicas con formas precisas para el abordaje terapéutico. Como estudiante de Medicina se torna abrumadora y excitante la posibilidad de conocer lo variopinto de esta disciplina, primero porque mantiene latente una angustia relacionada con ser lo suficientemente hábil y conocedor para no proferir sufrimiento a alguien más por errores propios, y lo segundo por lo regocijante de ir creciendo de la mano de la literatura y los maestros en la visión de esta profesión. Cada rotación por cada piso del hospital, fue elaborando en nosotros, los estudiantes, una visión de mundo que nos cambió la vida. Ahora estamos inscritos en el lenguaje del cuerpo médico y nuestro rol en la sociedad supone la decisión de dedicar gran parte de la vida a pensar en estos temas; desde la copiosidad de la Medicina interna con la pericia farmacológica que la caracteriza, la Pediatría con su capacidad para ajustar lo terapéutico a la dinámica propia del crecimiento y la Gineco-Obstetricia en la que se acompaña el milagro maravilloso del nacimiento y se atiende la salud del cuerpo femenino; fuimos labrando nuestra personalidad para enfrentarnos de cara a esta batalla contra el sufrimiento humano. La misión de hoy, retroalimentando desde mi corazón esta experiencia bella de rotar por cirugía, es comentar epílogos de mis aprendizajes en este camino y agradecer a los maestros y pacientes por sus valiosas lecciones.

Difícilmente puede uno hacerse una idea de lo que representa la cirugía sin estar en intimidad con ella; desde una perspectiva ajena, puede verse reducida al acto quirúrgico, que si bien es lo más bello de esta cara de la medicina, no es lo único. Cada ronda matutina por el servicio de cirugía general me permitió conocer las particularidades de la terapéutica del orden quirúrgico. Pude acercarme, entonces, a la nutrición, resignificándola desde un modificador de factores de riesgo a una medida terapéutica puntual; cada paciente con problemas quirúrgicos tiene sus particularidades

Palabras clave: cirugía general, educación médica, docentes médicos, rol del médico, historia.

Key words: general surgery; education, medical; faculty, medical; physician's role; history.

Fecha de recibido: 01/06/2017 - Fecha aceptación: 05/06/2018

Correspondencia: Juan David Lobo Hernández. Carrera 19 \# 35 Norte-7 21 parque residencial Ínter plaza Norte, torre 1, apartamento 307. Teléfono: 310- 7222794. Armenia, Quindío, Colombia. Correo electrónico: j-d-lobo@hotmail.com

Citar como: Lobo-Hernández JD. El quirófano: entre recomendaciones científicas y el arte de operar. Rev Colomb Cir. 2018;33: 247-49. https://doi.org/10.30944/20117582.68 
nutricionales que hacen que el médico se vea enfrentado a usar sus aprendizajes para indicar, de manera adecuada, la forma en que el paciente nutrirá su organismo mientras su problema se ve abordado satisfactoriamente, y si bien había visto modificaciones al rumbo de la salud en pacientes desde lo nutricional, como la efectiva dieta DASH para personas que padecen hipertensión, nunca había visto de una manera tan directa la forma en que la nutrición es fundamentalmente terapéutica, verbigracia en pacientes con fístulas intestinales de bajo gasto o pancreatitis, en donde hace parte de las indicaciones imprescindibles para la resolución de la patología. Más que ese carácter de relevancia que toma lo nutricional, quiero comentar esa filigrana con la que se manejan los problemas desde lo quirúrgico con la capacidad de ver al paciente en lo más general de su organismo y su persona. No digo que sea una característica única de la cirugía; me llama la atención es la forma en la que la ejecuta, debido a que supedita en el médico la valoración objetiva de una persona para saber si se beneficia de la ayuda quirúrgica que proponen como acto estético las manos del cirujano, además de realizar la planificación del acto quirúrgico en consentimiento del enfermo y sus seres queridos donde se hace vital prestarle atención hasta el más mínimo detalle como lo nutricional, el vaso que sangra de manera activa y la valoración pronóstica de la recuperación posquirúrgica y cicatricial del paciente con sus respectivas indicaciones.

En seguidilla, pude aproximarme a las recomendaciones basadas en la evidencia para la atención de pacientes con problemas quirúrgicos de una manera especial; me refiero a la forma en que la cirugía evoca ese carácter artístico en quien la practica. He imaginado infinidad de veces el momento maravilloso en que el doctor Borráez con la astucia de combinar sus vastos conocimientos en cirugía y la "malicia indígena" de un colombiano brillante, decidió aumentar de manera artesanal el continente abdominal del paciente que le llegó una noche del 94 con la bolsa de polivinilo que se volvería un aporte ontológicamente criollo para pacientes con evisceración o cierres temporales de pared abdominal; es bello cómo logra formular esa medida terapéutica buena, bonita y barata para patologías tan complejas. Esto me hace pensar que latía dentro de su pecho ese amor profundo por el arte del tratamiento médico, en donde el quirófano se volvió el escenario de una obra que se reproduciría en el mundo por millones de hábiles cirujanos con pacientes al borde del abismo y familiares depositando toda la confianza en la motricidad fina y la experiencia de quien opera.

No siendo suficiente con la visión humana del enfermo y la pericia artística del acto quirúrgico, en esta rotación aprendí la deontología del médico en la urgencia. Éste se ve enfrentado a un conflicto interno en el cual es lógico sentirse angustiado porque alguien más se ve amenazado en su estado vital, así mismo, es lógico que el tratante revista sus nervios de acero y mantenga una calma impresionante para lograr ordenar lo aprendido y realizar la examinación e indicaciones, de tal manera en que la urgencia logre conducirse hacia la recuperación del enfermo o del accidentado. Esta antinomia que enuncio entre estos dos momentos lógicos, pugna dentro del pecho y la mente del médico, por lo que agradezco a los maestros el habernos enseñado de manera paraverbal e íntima, esa forma no científica de adquirir habilidades personales que van a trasplantarse de la sala de simulaciones a la vida real.

Para concluir, recojo diciendo que los ojos de águila son para identificar oportunamente los signos de las entidades que requieren ayuda quirúrgica, junto a los pequeños detalles que promueven o complican la recuperación; manos de seda para hacer artesanía con tejidos vivos donde el resultado más bello es la sonrisa del enfermo recuperado reunido con su familia; y corazón de león para enfrentar con una actitud de terapeuta, ese hilo que delimita la vida y la muerte en la presentación aguda de entidades que amenazan la vitalidad de una persona, espantando la oz de "la pelona" con un rugido hipocrático y la ayuda divina del santo espíritu. 
Agradezco entonces a mis profesores por poner lo mejor de sí en acompañarnos en estos aprendizajes. Sin esa forma personal de colaborarnos a mejorar y sus regaños reiterativos pero constructivos en la mayoría de ocasiones, no tendría tantos aprendizajes que hoy valoro y que sé que mis compañeros de curso, con sus habilidades brillantes y particularidades personales, recibieron a su manera para beneficio de los pacientes. A ellos, mis compañeros, agradezco por haber sido docentes ad honorem de todo este proceso; sin su valiosa ayuda y su tolerancia inacabable, no sería lo mismo enfrentarme a una valoración diagnóstica o terapéutica. A los pacientes, gracias por enseñarme el mundo de la medicina desde lo más puro de la cultura en su forma de experimentar las dolencias; y a mi Dios, gracias por intervenir en el proceso terapéutico y tener esa capacidad de convertir la tragedia humana en valiosos aprendizajes.

\section{Agradecimiento}

A los docentes del área de Cirugía de la Facultad de Ciencias de la salud de la Universidad del Quindío, por su dedicación a la docencia y el bien social que hacen siendo excelentes profesionales. 